\title{
Entre la espada y la pared. El fracaso del primer experimento autonómico español en Cuba, 1897-1898
}

\section{Laura Muñoz}

Instituto de Investigaciones Dr. José María Luis Mora, México

lmunoz@institutomora.edu.mx

Sánchez Andrés, Agustín, Entre la espada y la pared. El fracaso del primer experimento autonómico español en Cuba, 1897-1898, Castelló de la Palma, Universitat Jaume I, 2020, 273 p.

Quiera Dios que este plan curativo Sea eficaz y todavía se llegue A tiempo de atajar el mal. Arsenio Martínez Campos

Ya circula en la Colección América, la colección que dirige Manuel Chust Calero en la editorial de la Universidad Jaume I, el libro más reciente de Agustín Sánchez Andrés. Se trata de un muy completo estudio acerca del primer experimento autonómico español en Cuba, importante no sólo para las Antillas en el momento y por el proceso recorrido hasta su instauración, sino porque se sentaron las bases afirma el autor- para la incorporación del autonomismo a la teoría política española. Construido a partir de catorce capítulos, el libro aborda en cada uno de ellos un aspecto del camino seguido hasta llegar a la instauración del régimen autonómico en Cuba y su corta existencia. Aunque los primeros proyectos para establecer un régimen autonómico son anteriores al periodo estudiado en el libro que comentamos, la posibilidad de que España lo concediera comenzó a ser parte del debate político en la década de 1860. Ese pensamiento político se iría nutriendo con los aportes de las experiencias británica y canadiense -propone el autor- a partir de

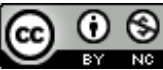

4.0 Internacional 


\section{Laura Muñoz}

la segunda mitad de la década de los sesenta del siglo XIX. Sin embargo, en las siguientes tres décadas ninguno de los gobiernos metropolitanos aceptó conceder una autonomía política a Cuba o Puerto Rico sino hasta las postrimerías de la centuria, cuando ya fue demasiado tarde.

Los títulos elegidos reflejan cabalmente cada etapa: la resaca de la revolución, el proyecto de autonomía colonial de junio de 1886, la adopción del autonomismo por el republicanismo español, el fracaso del reformismo asimilista y las primeras fisuras en el bloque dinástico, el fallido experimento canovista, la tardía conversión del Partido Liberal al autonomismo, la materialización del sueño autonomista, el nuevo marco de relaciones con las Antillas, las reacciones hacia el nuevo régimen cubano, los primeros pasos del Gobierno autonómico, los Estados Unidos contra la autonomía cubana, las primeras escaramuzas parlamentarias, las Cortes y el nuevo marco de relaciones con ultramar, el régimen autonómico durante la guerra Hispano-norteamericana.

El título mismo de la obra expresa en unas cuantas palabras la situación vivida: entre la espada y la pared, el reducido margen de maniobra que tuvieron los autonomistas para lograr que sus demandas fueran instauradas, así como la situación del gobierno español ante la inminente pérdida de Cuba. El prólogo y el epílogo abren y cierran la narración de todo el proceso. El prólogo coloca al lector en el conocimiento de los antecedentes que permiten comprender el camino recorrido para lograr la autonomía, conocer del respaldo de diversos sectores de la opinión pública y del espectro político en las Antillas y en la metrópoli y entender el funcionamiento del régimen autonómico, de vida tan breve.

El texto, muy documentado, bien escrito, con un estilo muy claro y sin rodeos -a pesar de la extensión de la obra, revisa el tema en cada etapa, desde diversas perspectivas, dialogando con la historiografía previa sobre el movimiento autonomista cubano. Destaca las características y los aportes de la historiografía española, así como de la cubana, tanto la insular como la de la diáspora. Y a diferencia de esa "literatura especializada que se ha centrado sobre todo en analizar los orígenes y trayectoria del Partido Liberal Autonomista de Cuba" (p. 15) la contribución de Sánchez Andrés radica en estudiar cómo el desarrollo del 
autonomismo antillano al paso del deterioro del modelo de relaciones coloniales de la última parte del siglo XIX, consintió que "las tesis autonomistas fueran siendo asumidas de manera progresiva por sectores políticos metropolitanos cada vez más amplios y diversos", (p. 16). Esta propuesta del autor, que él resume en dos líneas, la encontramos minuciosamente mostrada a lo largo del libro, analizando diversas aristas, y desemboca en el examen del funcionamiento del régimen autonómico.

En el primer capítulo se muestra el paulatino ascenso de los autonomistas y el despliegue de una intensa actividad que impactó el debate político español relativo a las colonias antillanas, aun cuando, como bien alerta el autor, no se deben sobredimensionar los resultados. No obstante, si resulta muy interesante seguir, en especial, la discusión en las diversas publicaciones periódicas de la época, correspondientes a las diversas agrupaciones políticas.

El planteamiento de las tesis autonomistas se dio en las Cortes españolas hacia mediados de 1886. Este es el tema del segundo capítulo, que aborda de manera pormenorizada todo el debate y los intentos de llevar a cabo la propuesta. Marca las diferencias con los proyectos de 1811 y 1823 e identifica en el Informe Político elaborado por los comisionados coloniales en 1867, la interpelación presentada a la Corte, en 1869, por el diputado puertorriqueño Luis Padial -y elaborada en conjunto con el cubano Rafael de Labra, así como en la política colonial de Gran Bretaña en Canadá las verdaderas fuentes del proyecto de 1886, en especial el proyecto PadialLabra.

A propósito de la empatía de una parte del republicanismo español con la causa de los autonomistas cubanos que salió a relucir durante los debates del proyecto de autonomía colonial de 1886, el tercer capítulo analiza la adopción que hizo aquel grupo político del autonomismo. Contribuye a la narración acerca de los avatares de la propuesta autonómica en España entre los diferentes partidos y ofrece una mirada a la alianza entre autonomistas y republicanos que se logró, aunque no completamente, después de un largo proceso acelerado con la crisis de 1895.

De particular provecho resulta el siguiente capítulo que evidencia las distintas posiciones políticas españolas frente al autonomismo antillano, las divergencias incluso dentro de esos grupos políticos y la influencia que tuvieron las figuras 


\section{Laura Muñoz}

dirigentes en el sesgo que tomaron algunas de las decisiones para establecer un modelo de relaciones con las Antillas. Atento a la década de los años noventa, este capítulo permite observar el desgaste de los liderazgos de los dos partidos hegemónicos: Antonio Cánovas del Castillo y Práxedes Mateo Sagasta. El autor va introduciendo a los personajes que permiten seguir una reconstrucción puntual del escenario político español y entender los vaivenes de las diferentes posiciones incluso las divergencias al interior de las mismas agrupaciones, y los efectos en éstas de los acontecimientos en la isla a partir de 1895. Progresivamente se fue asimilando que la pacificación de la isla requería la concesión de la autonomía. En este periodo destaca, desde luego, la figura de Segismundo Moret. Se da seguimiento a todos sus esfuerzos y al despliegue de su intensa actividad para lograr el éxito del proyecto autonomista. Al fracasar las gestiones pacificadoras de los notables autonomistas, estos permanecieron al lado de la metrópoli. En esta situación, el Partido Autonomista de Cuba entró en profunda crisis, pues parte de sus dirigentes más destacados y sectores importantes de sus bases se pasaron al bando de la revolución.

El texto sigue los vericuetos de los enfrentamientos en España, de las estrategias desplegadas, de los efectos que se vislumbraban de la intervención estadounidense en la situación cubana y de las acciones tomadas en la metrópoli. La concesión de una autonomía amplia para Cuba era, quizá, la última oportunidad para evitar un conflicto con Estados Unidos.

Con el nuevo gobierno de Sagasta, con el que se inicia el siguiente capítulo, se acuerda conceder un régimen autonómico a Cuba y Puerto Rico, con la ilusión de que constituía la forma de no perder a Cuba frente a las aspiraciones de Estados Unidos y en el contexto de la guerra en la isla. Ramón Blanco fue el encargado de llevar la autonomía a la mayor de las Antillas. Pero como se constata con la lectura del texto, fue una movida política muy tardía.

El nuevo marco de relaciones con las Antillas es el eje del siguiente capítulo. Se hace referencia puntualmente a la constitución autonómica cubana y a los otros dos decretos, de carácter complementario pero necesarios, para hacer factible la autonomía. El primero de ellos hace extensivo a las Antillas, sin ninguna restricción, los derechos y libertades constitucionales que ya existían en la metrópoli, mientras 
que el otro decreto implantaba el sufragio universal masculino y la legislación electoral vigente en la Península, pero con algunas modificaciones. Un apartado se detiene en la doble naturaleza de las funciones del gobernador general y destaca todas las previsiones que estableció Moret, en particular en el mecanismo que garantizaría un cierto equilibrio de poderes entre el gobernador, el ejecutivo autonómico y el Parlamento auxiliar reservándose al gobierno de la metrópoli la solución de los conflictos que pudieran existir entre los tres. El capítulo en comento es uno de los centrales para conocer el funcionamiento del régimen autonómico, de cómo reprodujo de manera simplificada la estructura del gobierno metropolitano, de cuáles fueron sus influencias, y cuáles fueron sus alcances.

Las reacciones al nuevo régimen fueron inmediatas en España y en las Antillas y ese es el tema del siguiente capítulo. Hubo celebraciones en el sector que pensaba que el régimen autonómico era la única vía para pacificar Cuba y para evitar más muertes, así como entre las corporaciones económicas que vislumbraban la reanudación de las actividades productivas, pero no ocurrió entre la Unión Constitucional, que se opuso totalmente. El republicanismo sintió que le habían arrebatado una bandera y entre los partidos dinásticos hubo en general cierta incertidumbre hacia el resultado final de la instauración del autonomismo que podría desembocar en la independencia, con la que no estaban de acuerdo. En este escenario, Agustín Sánchez atiende al detalle el proceso, examinando la participación de las figuras políticas relevantes y los acontecimientos en Cuba y en la península.

El análisis no deja de lado la presencia y participación estadounidense y refleja el temor que existía ante una intervención, lo que implicó un acelerado traspaso de la administración cubana al nuevo orden autonómico. Sus primeros y apresurados pasos son estudiados escrupulosamente en el décimo capítulo. Uno de los asuntos abordados en éste y que discute con la historiografía cubana, se refiere a la incidencia del componente racial en el discurso autonomista. Sánchez Andrés afirma que "la mayoría de los dirigentes autonomistas consideraban que la sociedad insular, y especialmente los sectores negros o mulatos que constituían una gran parte de la población rural, no estaba preparada para la independencia. Ello no significa - 


\section{Laura Muñoz}

continúa el autor- que el autonomismo no se concibiera a sí mismo como una vía gradual hacia la consumación de una nacionalidad cubana”, (p. 170). El gobierno autonómico desplegó una campaña sistemática dirigida a los sectores negros y mulatos de la isla y se los llamaba a apoyar la bandera autonómica. Un segundo tema destacado en este capítulo se concentra en la actitud de los independentistas hacia el gobierno autonómico, quienes se retiraron de cualquier negociación que lograra un acuerdo -procurado por el gobierno autonómico- que impidiera la intervención estadounidense.

Hacia los últimos capítulos conocemos cómo se fue construyendo y desplegando la posición de Estados Unidos y cómo los acontecimientos empujaron a la intervención, considerada como inevitable. Mientras España pensaba que la autonomía era la última esperanza para conservar a Cuba, Estados Unidos no veía otra opción para salir de la crisis cubana que el establecimiento de un protectorado o una anexión, el dilema era, dice el autor "si llevar a cabo este propósito por medio de una intervención militar o esperar a un improbable éxito del régimen autonómico, concebido como una mera antesala para la anexión pacífica de la isla a los Estados Unidos”, (p. 186). En el relato queda evidenciada la ineficacia de las medidas adoptadas por el gobierno español, las concesiones otorgadas, y los esfuerzos del gobierno autonómico, Estados Unidos no apoyaría ninguna medida que ayudara al gobierno español ni reconocería al gobierno autonómico. En España mientras tanto, el cercano cambio de grupo político en el gobierno amenazaba la legitimidad del gobierno autónomo cubano.

La guerra con Estados Unidos provocó que el tema de la autonomía cubana pasara a segundo plano y que, por una parte, quedara vinculado a la guerra, y por la otra, al proyecto de ley de indemnidad. Fue relevante en este periodo cómo quedaron exhibidas las posiciones políticas en la metrópoli, ya fuera reflejando la falta de identificación con la aplicación de la autonomía en las Antillas (por la mayoría liberal) o subrayando la denuncia de la opresión colonial a la que estaban sometidos

Cuba y Puerto Rico (aducida por la minoría republicana) que veía en la autonomía una salida. 


\section{Laura Muñoz}

Finalmente, en el último capítulo acompañamos al autor en el examen que hace al gobierno autonómico en tiempos ya de la guerra hispanoamericana. Argumenta que las instituciones autonómicas desplegaron una intensa actividad durante su corta existencia, en contraposición a lo que afirma la historiografía cubana, y señala que la derrota española y la disolución de esas instituciones autonómicas fue lo que impidió que las medidas aprobadas pudieran aplicarse. No obstante, en opinión del autor, las reformas económicas implantadas fueron benéficas para la economía cubana a juzgar por el incremento de la recaudación de las aduanas y porque lograron paliar los efectos de la reconcentración, aun cuando no se logró resolver el desabasto.

El escrito de Agustín Sánchez no es para principiantes, el nivel de argumentación y despliegue de datos, hechos y nombres, exige al lector un conocimiento previo de la literatura sobre el tema y del periodo abordado. De manera contundente queda expuesto cómo tanto el gobierno español como el autonomismo se encontraron entre la espada y la pared y la claridad con la que vieron tanto los políticos españoles como los cubanos autonomistas hacia dónde se dirigía la isla, inmersos en una situación que provocaría la sustitución de una metrópoli débil, por "un protectorado permanente de la pujante potencia norteamericana sobre los destinos de Cuba", (p. 256).

El texto se inscribe en una preocupación intelectual de larga data del autor con el que ha consolidado una trayectoria. Constituye el análisis más completo y a profundidad de un tema que inició años atrás. Atiende ahora todos los ángulos y desde diferentes niveles, logrando así un acercamiento complejo que confronta las historiografías cubana y española y contribuye al conocimiento del experimento autonómico cubano y el tortuoso camino que siguió para alcanzar su instauración. Muestra que, con ésta se dieron las bases "para la incorporación del autonomismo a la teoría política española” y que fue un modelo para la organización políticoterritorial española cuando tuvo que transformarse.

El libro es un imperdible para todo aquel que quiera conocer a detalle cómo fue el proceso para lograr el establecimiento del régimen autonómico en Cuba. Fue, como sabemos, el último intento de la metrópoli para mantener la soberanía en la 
isla, buscando pactar con los separatistas y evitar la intervención estadounidense. Una estrategia tardía e infructuosa. El mal no se pudo atajar. 